\title{
The Lymphatic System: A Sometimes-Forgotten Compartment in Pharmaceutical Sciences
}

\author{
Malaz Yousef ${ }^{1,2}$, Daniela Amaral Silva ${ }^{1,3}$, Nadia Bou Chacra ${ }^{3}$, Neal M. Davies ${ }^{1}$, Raimar Löbenberg ${ }^{1}$ \\ ${ }^{1}$ Faculty of Pharmacy \& Pharmaceutical Sciences, University of Alberta, Edmonton, Alberta, Canada; ${ }^{2}$ Faculty of \\ Pharmacy, University of Khartoum, Khartoum, Sudan; ${ }^{3}$ Faculty of Pharmaceutical Sciences, University of Sao Paulo, \\ Sao Paulo, Brazil
}

Corresponding author: Malaz Yousef (malaz@ualberta.ca) or Raimar Löbenberg (rloebenberg@ualberta.ca), Faculty of Pharmacy and Pharmaceutical Sciences, Katz Group Centre for Pharmacy and Health Research, University of Alberta, Edmonton, Alberta, Canada T6G 2E1

Received, July 27, 2021; Revised, October 5, 2021; Accepted, October 6, 2021; Published, October 8, 2021

\begin{abstract}
The uniqueness of structure and physiology of the lymphatic system make it challenging to delineate all its contributions in the maintenance of our health. However, in the past two decades, the understanding of the importance of the function of this system has evolved and more appreciation has been drawn to the distinctive role it plays in health and disease. The lymphatic system has been linked to the pathophysiology of numerous ailments including cancer, various metabolic diseases, inflammatory conditions, and infections. Moreover, it has also been revealed that lymphatic targeted formulations can enhance the delivery of drugs through the lymphatic system to the bloodstream, bypassing the hepatic firstpass metabolism if taken orally, thus increasing the bioavailability, and improving the pharmacokinetic and toxicological profiles in general. Engineering lymphotropic preparations requires the understanding of many factors, the most important one being that of the physiological environment which they will encounter. Therefore, in this review, we detail the basic structure of the lymphatic system, then highlight the therapeutic and the pharmacokinetic benefits of drug delivery into the lymphatic system. The criteria for drugs and formulations used for lymphotropic delivery are also detailed with a contemporary overview of various studies undertaken in this field.
\end{abstract}

\section{OVERVIEW AND MAJOR MILESTONES}

About 20-30 litres of plasma are propelled daily out the arterioles into the interstitial spaces of the body tissues. Of this volume, about $90 \%$ is reabsorbed back through the venules (1). The remaining fluid is drained back to the circulation via the lymphatic vessels. These vessels, in addition to other tissues and organs, form the lymphatic system (1-3).

The lymphatic system primarily maintains fluid homeostasis but also plays a pivotal role in transporting dietary fat and lipophilic molecules and entities from the intestine to the bloodstream. Moreover, it is involved in all immunological processes and numerous diseases and metabolic disorders which will be discussed later in this review (4-6).

It was Thomas Bartholin who first gave the term lymphatics to this system in 1652 (7). Nevertheless, the earliest recognition of the lymphatic system dates to the $4^{\text {th }}$ century B.C.E. by Hippocrates and Aristotle (8). Throughout the following centuries, the importance of the lymphatic system with respect to health was largely overlooked. It was not until 1622 when this system regained recognition and was described by the Italian physician Gasaro Aselli who found the intestinal lymphatic vessels, that he called "lacteals" while dissecting a dog's abdomen (9). Aselli's work was published in 1627 after his death, and that was one of the many landmark discoveries in the $17^{\text {th }}$ century; the golden era for lymphatic system research $(9,10)$.

Again, key gaps in knowledge about various aspects of the lymphatic system remained understudied for a long time afterwards (10). Yet, three decades ago, the lymphatic system started gaining more scrutiny and interest. Advances in science have led to the salient understanding of the role of lymphatics and its link to numerous diseases. $(10,11)$. Major milestones in lymphatic system research spanning centuries are summarized in Table 1.

\section{STRUCTURAL ORGANIZATION OF THE LYMPHATIC SYSTEM}

The fluid surrounding body's cells is termed the interstitial fluid. When this fluid enters the lymphatic system, it is referred to as "lymph." It does so through the blind-ended lymphatic 
capillaries, which are sometimes termed, the initial lymphatics. From there, lymph drains into the collecting vessels, which passes through at least one, but usually several lymph nodes distributed throughout the body. Collecting vessels merge into grander trunks which empty into the ducts. Finally, the ducts return the lymph into the venous circulation, completing the circuit of fluid transport $(1,3,4)$.

Table 1. Milestones in lymphatic system discovery and research throughout different eras

\begin{tabular}{ll}
\hline Year & Marks related to lymphatic system \\
\hline 460-377 B.C & Hippocrates recognized some lymph nodes \\
in various body areas containing a "fluid \\
absorbed from the tissues" (8) \\
300 B.C** \\
Aristotle's detection of a lymphatic vessel. \\
He described them as "fibres" between \\
nerves and veins (8). \\
Discovery of gut lymphatics by the Italian \\
Physician Gaspare Aselli. He called them \\
"venae albae aut lacteae" or (lacteals) (9). \\
The French Physician Jean Pecquet \\
described the thoracic duct and its valves. \\
He also recognized that gut lymphatics \\
empty into the cisterna chyle and not the \\
liver as previous anatomists claimed (12). \\
Thomas Bartholin, a Danish anatomist, \\
coined the term lymphatic for the first time \\
which appeared in his book "vasa \\
lymphatica." He also confirmed the \\
findings of Pecquet and illustrated that \\
lymph from the intestine flows till it \\
reaches the thoracic duct and that from the \\
liver also do so separately (7). \\
Description of the morphology and \\
function of the lymphatic valves by the \\
Dutch botanist and anatomist Frederik \\
Ruysch (12). \\
Paolo Mascagni demonstrated the \\
lymphatic network of the entire body (13). \\
Arnold Heller noted the first description of \\
lymph propulsion, observed in collecting \\
lymphatic vessels in the guinea pig \\
mesentery (14). \\
3D graphic illustration of the liver \\
lymphatics by Leonetto Comparini (10). \\
$\mathbf{1 7 8 4 - 1 7 8 7}$
\end{tabular}

1992-present Discovery of the growth factor/receptor system and related findings by Kari Alitalo, his team, and other international teams (10).

2015

Discovery of the brain lymphatic system by a team led by Drs. Antoine Louveau and Jonathan Kipnis from the University of Virginia School of Medicine (15)

\section{Lymphatic Vessels}

Lymphatic Capillaries. Lymphatic capillaries, initial or terminal lymphatics are commonly interlaced with the capillaries in the connective tissues of various parts of the body except for bones and teeth $(16,17)$. These are blind-ended structures that are a one cell-thick layer of thin- walled endothelial cells (18). These cells are 10$60 \mu \mathrm{m}$ in diameter and possess a unique oak leaf shape $(17,19)$. They have a discontinuous or absent basement membrane acting as primary valves and overlapping button-like junctions (Figure 1) (20).

Anchoring fibres tie the initial lymphatics to the extracellular tissue matrices $(21,22)$. These elastic filaments protect the initial lymphatic from collapsing under high tissue pressure. They also sense the pressure in the intercellular space and signal the opening of the flap-like junctions for drainage of the lymph $(19,23)$.

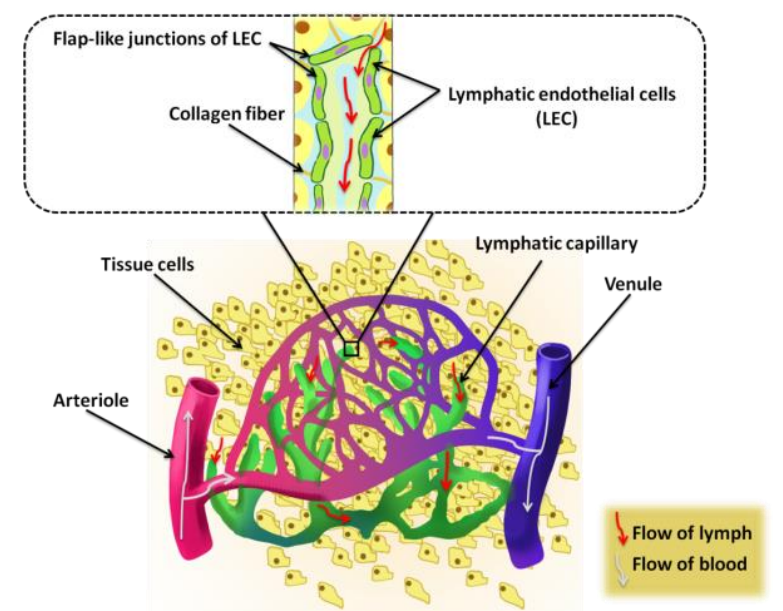

Figure 1. Illustration showing the lymphatic capillaries interlaced with the blood capillaries network (Left). The lymphatic capillaries or the initial lymphatics (Right) are closed-ended vessels, composed of a single layer of epithelial cells having flap-like junctions in between that serves as valves allowing the interstitial fluid to be drained into the lymphatics. These capillaries are anchored through filaments to the surrounding tissue which help them withstand the high pressure without experiencing a collapse. From https://commons.m.wikimedia.org/wiki/File:Illu_lymph_capil lary.png\#mw-jump-to-license

Lymphatic Precollectors. They are lymphatic vessels built of an endothelial layer of cells (19, 24). In regions close to the initial lymphatics, the endothelial cells of the precollectors still retain the oak leaf shape. The closer proximity to the collecting lymphatic vessels, the endothelial cells acquire a rhombic form like that of the veins $(6$, 25).

These vessels resemble the initial lymphatics in having no smooth muscle layer. Yet, they differ from them in having structured valves within, which are termed secondary valves. The valves here serve in preventing backflow into initial lymphatics (6). Having no smooth muscle layer, lymphatic precollectors rely on the inflow 
and outflow pressures of individual segments in pushing the lymph forward (3).

Collectors. The next structural vessel organizations in the lymphatic system are the collecting lymphatics. The walls of which are composed of an endothelium layer encircled by a smooth muscle cell layer and a layer of collagen fibres; the adventitia (26).

These lymphatic vessels get thicker as they merge. A new feature of these lymphatic vessels is the microcirculation or the "vasa vasorum" that delivers oxygen and nutrients to larger collectors (27). Moreover, the secondary valves here play structural and functional roles. They prevent lymph retrograde movement and also divide the collecting vessels into chambers (3, 26). Each chamber forms a contractile unit called the lymphangion, meaning "lymph heart". Contraction of lymphangions together with the proper functioning of the valves ensures the smooth unidirectional flow of lymph even against gravity in a standing posture (28).

Usually, many collectors drain into a lymph node, and typically but not always one collecting vessel exits the node. The former is the pre-nodal or the afferent lymphatics and the latter is one of the post-nodal or the efferent lymphatic vessels (29).

Trunks. Structurally, they are the larger counterparts of the lymphatic collectors (29). But functionally, there are some differences; in humans they funnel into two major ducts that return lymph back into the venous circulation. Two major trunks; the intestinal and the lower lumber, drain into a sac-like structure called the cisterna chyli, located at the base of one of the ducts; the thoracic duct $(3,30)$. Other major trunks (jugular, subclavian and broncho mediastinal) drain directly into ducts (31) as shown in Figure 2.

Ducts. The last part of the lymphatic network is the ducts. Eventually, the larger vessels merge into the lymphatic trunks, that empty into the venous circulation via the right lymphatic duct and the thoracic ducts (2) as depicted in Figure 2.

The right lymphatic duct is formed from the merger of the right jugular, the right subclavian, and the right bronchomediastinal trunks (29). It receives lymph from the right sides of the head, thorax, and right upper limb and drains into the junction of the right subclavian and right internal jugular veins (32). Lymph from the remaining parts of the body get through the thoracic duct into the junction of the left subclavian and left internal jugular veins (33). It is built of smooth muscle fibres and has a valvar system to prevent lymph backflow and blood reflux at the point where it meets the venous system $(33,34)$.

Summary of the order of lymph flow through the lymphatic network and the structure of each vessel is illustrated in Figure 3.

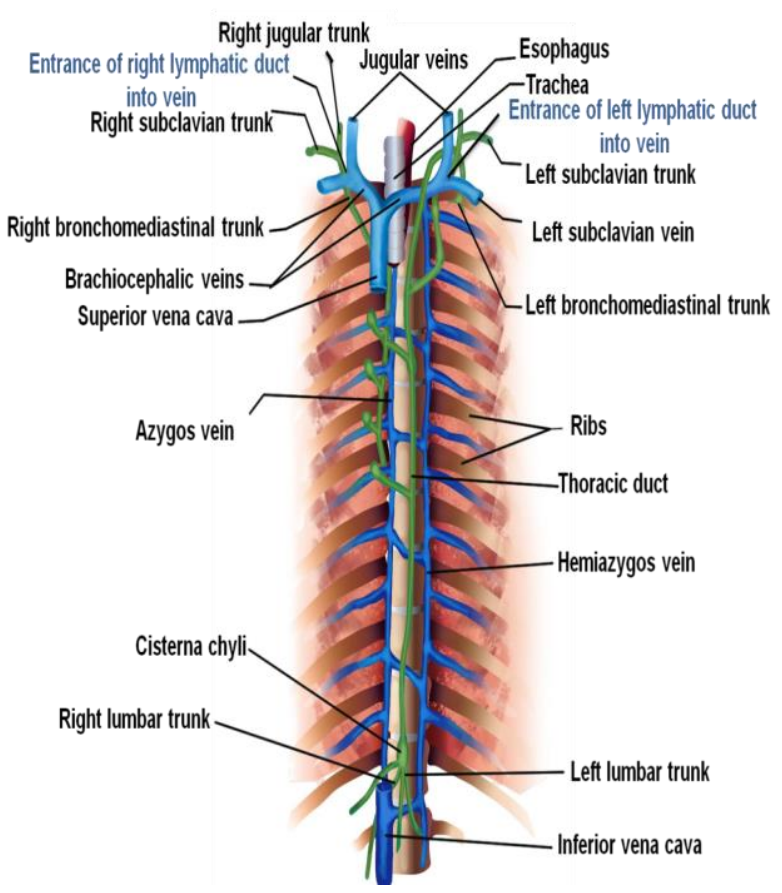

Figure 2. Major lymphatic trunks and ducts in the human body. The intestinal and the lower lumber trunks empty into the cisterna chyli, before draining into the thoracic duct. Whereas the jugular, subclavian and broncho mediastinal trunks funnel directly into the duct located on their side. The right lymphatic duct drains lymph into the junction between the right jugular and subclavian veins, whereas the thoracic duct empty into the junction of the same veins on the left side. From (29) with permission.

\section{Lymphatic Tissues and Organs}

The lymphatic tissues and organs are grouped as primary and secondary based on their functional roles (29). The primary lymphatic organs are the sites of lymphocyte formation and acquisition of immunocompetency and include the red bone marrow and the thymus $(29,35)$.

The secondary lymphatic organs are where immune responses occur. Lymphatic nodes, spleen and lymphatic follicles are members of this group (35). The first two (the lymphatic nodes and the spleen) are classified as organs because they possess an outer capsule of connective tissue, unlike the lymphatic nodules which lack it and as a result are considered tissues (29). There are numerous lymphatic nodules 
found within the mucous membranes lining the respiratory, gastrointestinal, and urinary tracts, termed mucosa-associated lymphatic tissues (MALTs) (36). Clusters of these nodules can be found in the tonsils and in the ileum of the small intestine these are referred to as Peyer's patches (37).

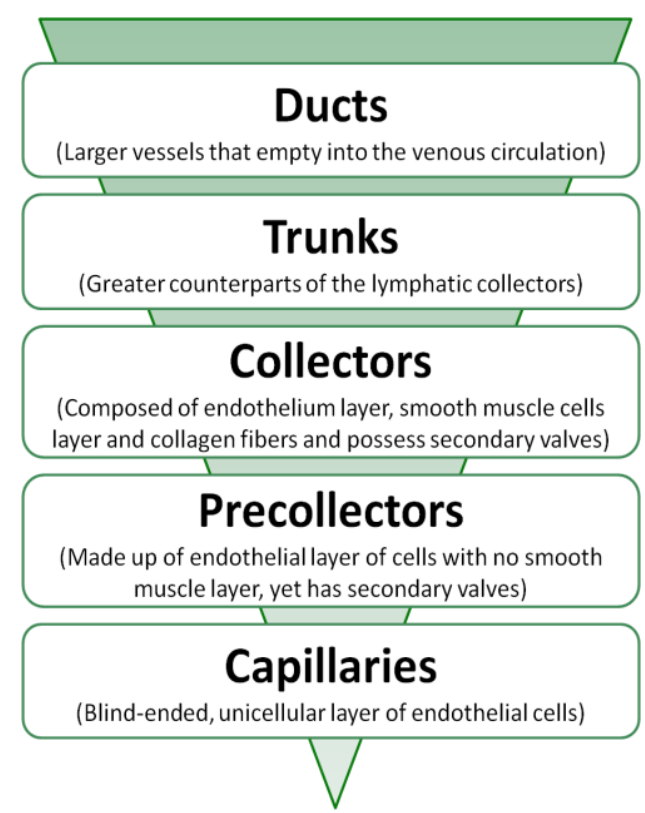

Figure 3. Lymphatic network of vessels starting from capillaries and ending with ducts.

Out of these different lymphatic organs and tissues, lymph passes only through the lymph nodes which will be detailed next.

Lymphatic Nodes. Lymphatic nodes resemble immunosurveillance units, which functionally serve in filtering the lymph and mounting immune responses against detected antigens (6).

These nodes are bean-shaped lymphoid organs placed throughout the body, most prominently near the mammary glands and in the axillae and groin. Lymph nodes range between 1 to $25 \mathrm{~mm}$ in length and are divided structurally into two major parts, capsule, and parenchyma (Figure 4). The capsule is a dense fibrous tissue that runs towards the interior of the node forming partitions called the trabeculae. The parenchyma has two distinct sections: the cortex and the medulla $(35,38)$.

The outer cortex houses lymphatic follicles or nodules. There are two types of lymphatic nodules: primary and secondary nodules $(39,40)$. The former consists of $\mathrm{B}$ cells surrounded by a loose network of dendritic cells. Upon encountering an antigen, the macrophages or the dendritic cells stimulates the development of the secondary nodules by the activation of the B cells which are bounded by cortical dendritic cells and macrophages form what is termed a germinal centre. Surrounding this centre there is a condensation of B cells, forming the outer part of the secondary nodule (40).

There are no lymphatic nodules in the inner cortex; instead, there are $\mathrm{T}$ cells and macrophages that migrate from other parts of the body. The macrophages cause the proliferation of $\mathrm{T}$ cells to combat antigens. The activated $\mathrm{T}$ cells do not reside in the lymph node but rather travel where there is antigenic activity (41).

Cells in the medulla are the antibodysecreting plasma cells that proliferate from the activated $\mathrm{B}$ cells in the outer cortex, in addition to the macrophages $(29,42)$.

Lymph drains into the nodes via the afferent vessels entering the nodes through its convex side. It follows a certain path crossing the sinuses within the node then exits through the efferent vessels emerging from the hilum (a depression on the concave part of the lymph node) (43). Cells might get into nodes with the lymph or through special blood vessels termed high endothelial venules (HEVs) (4).

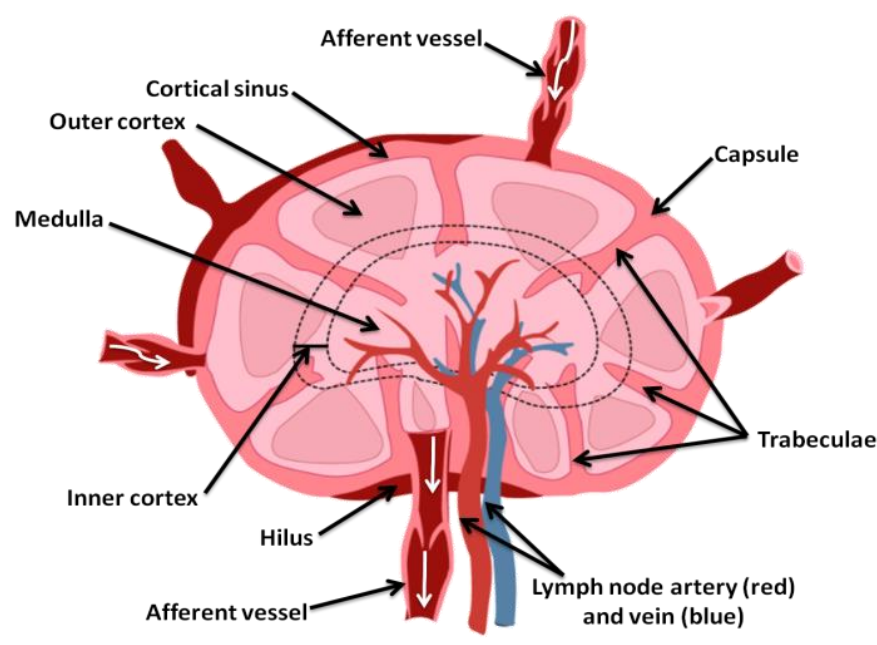

Figure 4. Structure of the lymph node. It is composed of the capsule and the parenchyma. The parenchyma encompasses the cortex and the medulla. The cortex is divided into outer and inner parts. The former contains the primary and the secondary follicles. The secondary follicles differ from the primary ones in having a germinal centre (activated B cells with dendritic cells and macrophages) surrounded by a condensation of $\mathrm{B}$ cells. Moving inwards there will be $\mathrm{T}$ cells and macrophages in the inner cortex, and antibodysecreting plasma cells with the macrophages sin the medulla. 


\section{Intestinal Lymphatic System}

The intestines are a part of the gastrointestinal organ system and a region in the body that exhibits unique morphology and function of the lymphatics that is not encountered anywhere else. Here the lymphatic system besides drawing out excessive fluids and mounting immunological responses, which are the roles of the lymphatics throughout the body, also facilitates the absorption of dietary lipids through its special lymphatic capillaries; the lacteals $(44,45)$. In addition, there are several vitamins and food nutrients that use this system to access and enter the systemic circulation.

Structurally, the intestinal lymphatics start with the lacteals, found in the intestinal villi. The lacteals funnel into pre-collecting and collecting vessels located in the mesentery, which in turn drain into the cisterna chyli at the posterior end of the thoracic duct (45).

As illustrated in Figure 5, lacteals range between 60 and $70 \%$ of villi length and are encircled by a mesh of blood capillaries and smooth muscle fibres. A cytoplasmic extension or filopodia is usually attached to the lacteal tip demonstrating the state of regeneration that the lacteals can undergo (30).

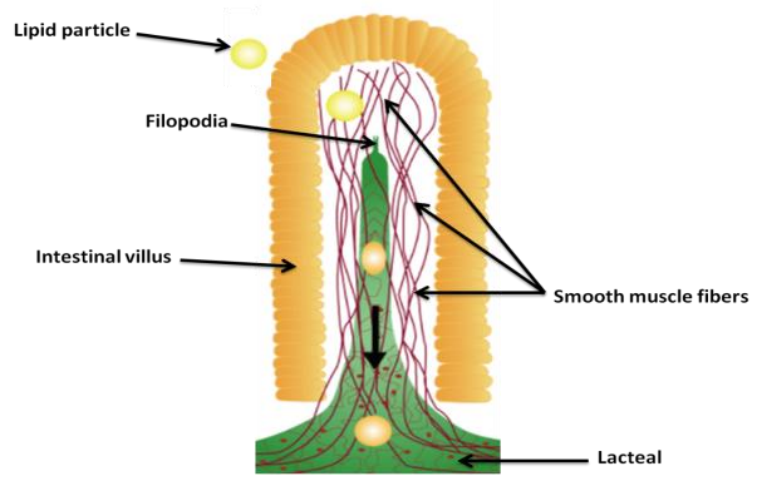

Figure 5. Structure of the intestinal lymphatic capillary (the lacteal). It constitutes nearly two thirds of the villi length and is surrounded by network of blood capillaries and smooth muscle fibres. It might have a cytoplasmic extension called filopodia, which indicates the state of active regeneration of the lacteals on which it appears. Lacteals play a vital role in up-taking absorbed lipids and draining them through the mesenteric lymph node into the thoracic duct before they enter into the systemic blood vasculature. Modified from (30) (Creative Common License).

The discontinuous button-like junctions between lymphatic endothelial cells of the lacteals indicates their functioning in lymph uptake. However, the transition to zipper-like cellular junction in the collecting lymphatic vessels reflects less permeability and the better containment that these vessels must prevent the leakage while transporting lymph (18). Cellular junctions of lacteals were also linked functionally to the chylomicron's entry into the lacteal (46).

Chylomicrons are the form into which lipids and lipophilic components are assembled to be up taken by the lacteals (47). Following their absorption, dietary lipids are hydrolysed into fatty acids and monoglycerides, then re-esterified to triglycerides in the endoplasmic reticulum of the enterocyte's apical membrane $(30,45)$. The triglycerides, cholesterol, cholesteryl esters, phospholipids, and the apolipoprotein are packaged into chylomicrons and set out from the basolateral membrane of the enterocyte (30). In order to access into lacteals, chylomicrons do not diffuse passively as claimed earlier, but rather are taken up actively through a mechanism involving molecular signalling that is yet to be fully understood (48). However, the vascular endothelial growth factor-A (VEGF-A) has been shown to modulate the cell-cell junctions in lacteals and blood capillaries (49), regulating the lipid uptake process via signalling pathways starting with the binding to the vascular endothelial growth factor receptor-1 (VEGFR-1) and its co-receptor, the semaphorin receptor (NRP1) as depicted in Figure 6 (30).

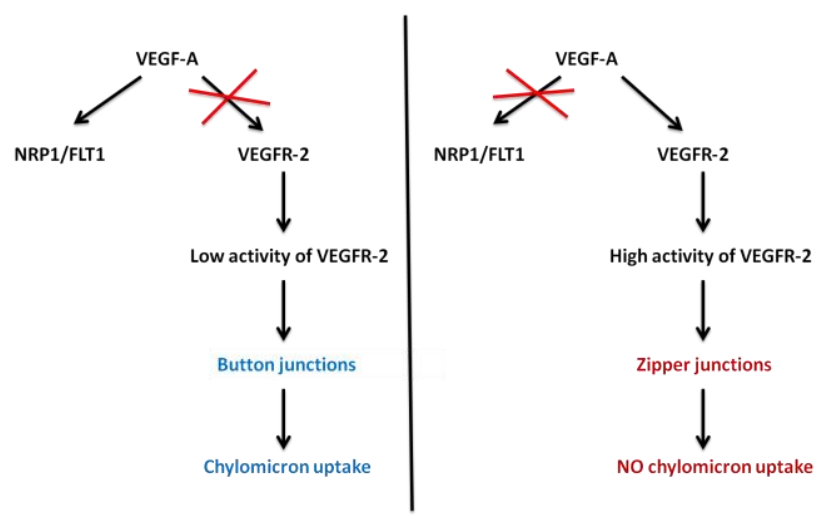

Figure 6. Schematic model of cell-cell junctions in lymphatic endothelial cells (LECs) regulating chylomicrons uptake through lacteals. The availability of the vascular endothelial growth factor-A (VEGF-A) for binding the NRP1/Fms-related tyrosine kinase 1 (FLT1) on blood endothelial cells (ECs) results in having the button like junctions between the LECs that enables the chylomicrons uptake into the lacteals. When the opposite is encountered and the VEGF-A binds the vascular endothelial growth factor receptor-2 (VEGF-2) on the LECs, that imparts the tight zipper junctions on the LECs and facilitates the transport rather than the uptake of the chylomicrons into the lacteals. Modified from (30). 
Lacteals are not the only lymphatic feature present within the intestine. There is another key component there, which is the Peyer's patch. These lymphoid tissues are located within the mucosal lining in the intestine. They compose a gateway for lymphatic voyage similar to lacteals and are also an immune surveillance site that encounters various ingested immune elicitors like bacteria, viruses and other factors $(4,50)$.

\section{LYMPHATIC SYSTEM ADDING THERAPEUTIC BENEFITS}

The overall lymphatic function is now thought to be associated with the pathophysiology of various diseases more than initially considered. Thus, lymphatics are an important target site for drugs and their delivery systems used in these conditions, especially lymph resident diseases such as cancer and some viral infections. Moreover, the lymphatic nodes play a central role in generating an immune response, thus they are considered a crucial target for vaccines $(4,42,51$, 52). For these indications, a new chapter in drug delivery has opened and various formulations have been developed while others are being investigated to target lymphatics through different routes of administration.

Next, the areas of intimacy between the lymphatic system and the pathophysiology of some disorders and diseases are summarized, with the various studies to exploit the lymph targeted delivery to add therapeutic benefits

\section{Cancer}

Being routes of trafficking through the body, lymphatic vessels are used by the malignant cells to spread. They are preferred over the blood vessels for this mission because of the lymphatic's broader vasculature, lower pressure gradient and higher permeability (53). Usually, the metastases occur in steps, the first of which is the colonization of the sentinel lymph node (4). This can occur through the pre-existing lymphatic vessels or newly formed ones resulting from the induction of tumour secreting growth factors (e.g VEGF-A, VEGF-C and VEGF-D) that stimulate the lymphangiogenesis (formation of new lymphatic vessels) to that node and beyond. Once in the first targeted node (a regional node), disseminating cancerous cells continue to do the same to promote more drainage of the growth factors to the node to aid in invading a distant node using the same strategy $(4,53-56)$. Other lymphatic markers have also been linked to cancer metastasis such as Prox-1 and Lyp-1 (56). Therefore, developing lymphotropic formulations for chemotherapeutic agents and lymphatic biomarkers could enhance their therapeutic outcomes, in terms of target specificity, drug resistance and toxicity.

It has also been delineated that, Lyp-1 is a nano-peptide that binds a specific receptor (p32) which is highly expressed on tumor-related lymphatics, macrophages, and cancer cells (57). The lymphatic targeting of the Lyp-1 achieved via a self-micro emulsifying delivery system (SMEDDS) resulted in decreasing the tumor size in 4T1 Tumor-bearing mice. Concomitant administration of the same peptide with the cytotoxic drug doxorubicin (Dox $\mathrm{HCl}$ ) exhibited a reduction of the cell viability from $74.3 \%$ to $49.6 \%$ after 48 hours of incubation in the MDAMB-231cell line. Thus, lymphotropic delivery of the Lyp-1 can be an effective way to combat tumors (58).

Another example is the cytotoxic anticancer agent doxorubicin that has achieved greater antitumor efficacy through a lymphotropic formulation. The subcutaneous administration of liposomal doxorubicin decreased the volume of auxiliary lymph nodes by $56.77 \%$ in comparison with the intravenous formulation that caused a $27.08 \%$ decrease in auxiliary lymph nodes size using rabbits inoculated with VX2 cells to develop breast cancer. Additionally, this resulted in an increase of the apoptotic cell count by 3.21 and 1.97-fold for the liposomal and the free drug preparations of doxorubicin, respectively. The inhibition of growth and the induction of apoptosis of tumour cells that the liposomal doxorubicin imparted was postulated to lead to higher lymphatic uptake of the developed subcutaneous formulation and the greater drug reaching the regional lymph nodes where metastasis occurs (59).

Moreover, the intravenous and oral administrations of a doxorubicin-quercetin conjugate (DoxQ) demonstrated 5 and 1.5 -fold increase in the area under the curve (AUC) compared with the unconjugated standard drug treatment (Dox), respectively. The volume of distribution (Vss) imparted with the intravenous DoxQ was $0.138 \pm 0.015$ where that of the doxorubicin was $6.35 \pm 1.06 \mathrm{~L} / \mathrm{kg}$ in male Sprague-Dawley rats. The oral Dox Q delivery system resulted in double the amount of Dox in the mesenteric lymph fluid than the Dox. The transformed pharmacokinetics and improved oral bioavailability of the DoxQ were attributed to the lymphatic transport of the drug conjugate with the lymphotropic antioxidant flavonoid quercetin (60). 
Paclitaxel is used for treating many cancer types, such as breast cancer, lung cancer, ovarian cancer among others (61). Reports on targeted paclitaxel nano-formulations supported its superior chemotherapeutic activity when administered through lymphatics. When incorporated in inhalable solid lipid nano-carriers (SLNs), paclitaxel resulted in tumour cells survival rate of $(19.34 \%)$ compared with $87 \%$ cell viability when free paclitaxel was administered intravenously in a mice lung cancer model. Moreover, the inhalable SLN-paclitaxel showed no toxicity upon prolonged treatment and about 20 times less concentration to inhibit $50 \%$ of cell growth $\left(\mathrm{IC}_{50}\right)$ than intravenously administered paclitaxel (62).

SLNs were also used for the cytotoxic agent etoposide. The study used mice with Dalton's lymphoma to compare the biodistribution of radiolabeled free and nanoparticle-based etoposide through three routes of administration, i.e., subcutaneous, intravenous, and intraperitoneal. Following 24 hour after administration, the subcutaneous route exhibited greater drug uptake by 8 -fold and 59 -fold than the intraperitoneal and the intravenous ones, respectively. Likewise, subcutaneous administration also showed a relatively low tissue distribution, suggesting lesser systematic side effects of the drug. Therefore, the subcutaneous injection was suggested to be a better route for administering chemotherapeutic drugs targeting lymphatic-related malignancies (63).

Intraduodenal administration of methotrexate solution and SLNs formulations came in favour for the nano-formulations regarding the chemotherapeutic effect as a 10-fold increase in lymphatic drug uptake was reported with drug-loaded SLNs as opposed to the free dug solution using dialysis membrane and rat models (64). Thus, the oral bioavailability of methotrexate can be improved via lipid-based formulations favouring lymphatic transport.

Zara et al also studied oral lymphotropic delivery for cancer drugs using SLNs taking idarubicin as a model drug. The Intraduodenally administered formulations of idarubicin showed a 21-fold increase in the area under the plasma concentration time curve compared with the drug solution. Again, the greater biodistribution in the lymphatic system appeared to serve in decreasing the idarubicin concentration in the heart and thus reducing its cardiotoxicity. The 30 -fold increase in the elimination half-life of the idarubicin loaded SLNs suggested its potential use as a sustained release delivery system (65).
9-Nitrocamptothecin (9NC) is a potent antitumor agent that is used to treat hepatocellular carcinoma. The liposomal formulation of this drug (9NC-LP) has been shown to demonstrate a greater antiproliferative effect and fewer side effects in a nude mice xenograft model of HepG2 cell line in comparison with the free drug. The higher dose of the 9NC-LP $(2.5 \mathrm{mg} / \mathrm{kg} / \mathrm{d})$ repressed cancer growth by nearly $87.02 \%$ and the lower dose scored $41.66 \%$ tumour growth inhibition after three weeks, without any drugrelated death. Nevertheless, over half of the animals died on day 14 after administering 2.5 $\mathrm{mg} / \mathrm{kg} /$ day doses of the free drug. The observed effects with the 9NC-LP systems were attributed to their lymphotropic delivery (66).

Hyaluronic acid (HA) is a natural polymer transported via the lymphatics and when coupled with the chemotherapeutic agent cisplatinum (Pt), it made a successful local pulmonary delivery system with greater platinum concentration in the lung and draining lymph nodes as reported by Xie et al (67). A similar approach was considered with hyaluronan-cisplatin (HA-Pt) nanoconjugate to treat head and neck squamous cell carcinoma (HNSCC). In a developed orthotopic metastatic xenograft model of HNSCC, HA-Pt nanoconjugate achieved complete treatment success for $57 \%$ of the female mice whose group also showed significant hindrance of the HNSCC progression in contrast to the standard therapy group (p < 0.05) (68).

All previous examples reinforce the importance of lymph-targeted delivery for cancer treatment. However, the lymphatic system is also related to other diseases, as discussed next.

\section{Inflammatory Conditions}

Inflammation is a mechanism of protection against various pathogens and irritants (69). It is characterized by the expansion of both blood and lymphatic networks (angiogenesis and lymphangiogenesis, respectively). Whereas the proliferation of blood vessels exacerbates the inflammation, lymphatics were found to aid in containing the aggravation of this condition (70, 71). The reported mechanistic reasons underlying this was based on the formed lymphatic vasculature acting as clearance conduits, alleviating oedema, and decreasing the levels of pro-inflammatory mediators and immune cells (69). The molecular mechanisms involved in some inflammatory diseases like skin inflammation (72, 73), inflammatory bowel disease (IBD) (74) and rheumatoid arthritis (RA) (75) and others have been connected to lymphatic biology (69). 
Developing delivery systems of lymphangiogenic factors would increase the potential of effective alleviation of inflammatory pathologies. Yet, limited studies are available on this targeted approach. A recent report showed that the antibody-mediated delivery of the vascular growth factor-C (VEGF-C) reduced skin inflammation in two mice models due to its accumulation in the affected tissues and stimulation of the expansion of the lymphatic vascular network (69).

Another study on the lymphatic related effects on inflammation involved the use of the tissue necrosis factor (TNF). It is a proinflammatory mediator that was linked to rheumatoid arthritis through its induction of neutrophils which when elevated and impairs the lymphatic pumping and aggravates the inflammation associated with rheumatoid arthritis. A study by Aldrich et al revealed that the intradermal administration of the anti-TNF drug, etanercept, improved lymphatic functioning and reduced the swelling in a rat model of collageninduced arthritis (CIA) (76).

Intriguingly, many current treatments for inflammatory diseases, such as tocilizumab and infliximab affect lymphangiogenesis (77, 78). These proteins are administered through subcutaneous and intravenous routes and their relatively large size makes at least part of the administered dose to be taken up by the lymphatics (4). Thus, they would exhibit lymph related changes that account for their antiinflammatory action. Yet, the door is still open for research in treatment options using the lymphatic system-inflammation overlap.

\section{Metabolic Diseases}

Accumulating evidence supports the crosstalk between lymphatics and adipose tissue. The link between lacteal permeability and transport has been already established with adult obesity (46, 79). The disturbance in the signalling pathways modulating the cell-cell junctions of lacteals would result in leakage of fat-rich lymph and its accumulation, leading to diet-induced obesity (46). Insulin sensitivity has also been found to tie with the proper intestinal lymphatics functioning (80). Hyperinsulinemia and inflammation arising from obesity can also affect the lacteals integrity, progressing to deadly complications (30). Nevertheless, there is still an open area of research to dig in here and in other metabolic diseases which were connected to the lymphatic system such as hypertension (81), atherosclerosis $(82,83)$ and others (4).
In this disease group, there hasn't been translational development of drugs targeting lymphatics for the various indications that have been associated with the lymphatic system yet. Nonetheless, there are drugs that are being used to treat some of these metabolic diseases which have been found to have higher therapeutic efficacy when administrated through delivery systems that favour lymphatic transport. In the aforementioned studies, the reasons behind the better outcome were solely related to the pharmaceutical rather than the pharmacological reasons; with the lymphotropic formulations offering higher bioavailability and preventing the first-pass metabolism. A list of these drugs is in Table 3.

\section{Infections}

As a system hosting immune surveillance centres and paving immune trafficking pathways throughout the body, the lymphatic system plays a vital role when antigenic invaders enter the body (3). Of special importance are the ones which take advantage of their accessibility to the lymphatics and utilize it to disseminate. Persistent HIV replication was connected to low lymphatic concentrations of the antivirals $(84,85)$. The list of other infections includes hepatitis (86), Ebola virus and recently the novel human coronavirus, SARS-CoV-2 was added to it (87). This data suggested lymphatics as a therapeutic target that would aid in eradicating certain challenging infections.

One example involves the link of the efficacy of the antivirals in downregulating the replication of the human immunodeficiency virus (HIV) in lymphatic tissue which was revealed to be associated with the lymph node concentration of antiretroviral drugs $(88,89)$. In support of this contention, the administration of subcutaneous nanoparticles in macaque monkeys indinavir extended the plasma residence times and increased the concentrations of indinavir in the lymph nodes of HIV-2 positive animals. This in turn caused a considerable reduction in the viral RNA load and an incremental increase in the $\mathrm{CD}^{+} \mathrm{T}$ cell count $(89)$.

\section{PHARMACOKINETIC BENEFITS OF THE LYMPHATIC SYSTEMG}

In addition to improving the therapeutic outcomes, lymphotropic delivery can add new possibilities for drugs of low solubility and those that are subjected to the hepatic first-pass effect. Such formulations can increase drug bioavailability, impart higher drug exposure, and lower toxicity by providing a by-pass route of the 
hepatic circulation to enable greater systemic access $(4,51)$. Table 2 summarizes various studies that reported lymphotropic formulations used to improve the therapeutic effects for different indications by enhancing the pharmacokinetics profile of drugs.

\section{REQUIREMENTS FOR LYMPHOTROPIC FORMULATIONS}

Formulations for lymphatic drug delivery, whether for targeting a lymph related disease condition or getting through the lymph to the general circulation- all have certain general requirements that affect their performance. These formulations include lymphophilic emulsions, microemulsions, self-emulsifying and self-micro emulsifying drug delivery systems. Additionally, numerous nanoformulations (e.g., polymeric nanoparticles, nanostructured lipid carriers, solid lipid nanoparticles and others) have also been considered $(11,53,56)$.

Nano-sized formulations are found to be superior to actively target lymphatics, especially those which are lipid-based (53). Such formulations are better candidates for lymphatic drug delivery. However, the uptake of these formulations into the lymphatic conduits depends on some factors, such as the route of administration (4). The intravenous administration of cytotoxic agents is reported to result in limited tumour uptake of the drug due to a faster clearance by the phagocytic system (102). An example of such effect has been encountered with the etoposide (Section 4.1). In addition, the intradermal route may enhance the lymphatic uptake in comparison with the intramuscular and the subcutaneous routes because of the elevated interstitial pressure and faster flow of lymph within the skin than in other interstitial sites (103). Likewise, other features such as the particle size, surface charge, hydrophobicity and types of lipids used also affect the lymphatic voyage $(53,56)$.

The molecular weight, partition coefficient, triglycerides solubility are the main criteria considered for drugs incorporated in lymphotropic formulations $(53,56)$. Other factors like surface area polarity and $\mathrm{pk}_{\mathrm{a}}$ have also been reported to play a role in drug-chylomicron association and thus the intestinal lymphatic uptake (104).

Requirements for both drugs and formulations targeting lymphatics are summarized in Table 3.

\section{CONCLUSIONS}

Over the last two decades, the functional importance of the lymphatic system in a wide range of diseases has become more evident. Thus, the lymphatic system itself is arising as a potential drug targeting avenue that could enhance the therapeutic outcome of such conditions. There are many studies that have focused on cancer and metastasis and the lymphatic system, however, translational studies on the lymphotropic formulations for therapeutic purposes is still in their infancy for many other disorders including inflammatory and metabolic ones in addition to various infections. Moreover, lymphotropic formulations have been linked to improved bioavailability and pharmacokinetic profiles especially for drug species liable to the first-pass metabolism. Optimized lymphatic targeted drug delivery requires a thorough understanding of the physiology of this system. Therefore, future studies would focus on understanding the detailed mechanisms of the entry and voyage of the lymph and mimicking the endogenous behaviour of lymph transported materials.

CONFLICT OF INTEREST. None.

Table 2. Lymphotropic formulations of drugs targeting various ailments.

\begin{tabular}{|c|c|c|c|c|}
\hline Formulation & Drug & Main Indication & Remark & Reference \\
\hline \multirow[t]{2}{*}{ SMEDDS } & Halofantrine & Antimalarial & $\begin{array}{l}\text { Lymphatic uptake of the SMEDDS } \\
\text { formulation reached } 27.4 \%\end{array}$ & (90) \\
\hline & Valsartan & Antihypertensive & $\begin{array}{l}\text { The AUC for the SMEDDS was } 607 \mathrm{ng} \\
\mathrm{h} / \mathrm{mL} / \mathrm{hr} \text { in comparison to } 445.36 \text { and } 1.36 \\
\mathrm{~h} \text { for market formulation }\end{array}$ & (91) \\
\hline
\end{tabular}




\begin{tabular}{|c|c|c|c|}
\hline $\begin{array}{l}\text { Microemulsion/ } \\
\text { SMEDDS }\end{array}$ & Raloxifene & Osteoporosis Agent & $\begin{array}{l}\text { in vitro intestinal permeability studies } \\
\text { demonstrated that the microemulsion } \\
\text { exhibited significantly higher permeation } \\
(90 \%) \text { compared to the plain drug } \\
\text { suspension }(41.06 \%)\end{array}$ \\
\hline
\end{tabular}

\begin{tabular}{|c|c|c|c|c|}
\hline Liposomes & Cefotaxime & Antibiotic & $\begin{array}{l}\text { Bioavailability of liposomal cefotaxime } \\
\text { was approximately } 2.7 \text { times higher than } \\
\text { that of the aqueous solution }\end{array}$ & (93) \\
\hline \multirow{5}{*}{ SLNs } & Tobramycin & Antibiotic & $\begin{array}{l}\text { The AUC of tobramycin in SLN } \sim 120 \text {-fold } \\
\text { greater than that following IV } \\
\text { administration of tobramycin solution }\end{array}$ & (94) \\
\hline & Clozapine & Antipsychotic & $\begin{array}{l}\text { Higher SLN bioavailability than that of the } \\
\text { suspension }\end{array}$ & (95) \\
\hline & Carvedilol & Antihypertensive & $\begin{array}{l}\text { SLNs had higher uptake to the CaCo- } 2 \text { cells } \\
\text { than the drug solution owing to higher } \\
\text { lymphatic transport }\end{array}$ & (96) \\
\hline & Nimodipine & $\begin{array}{l}\text { Prophylaxis of stroke } \\
\text { and hypertension }\end{array}$ & $\begin{array}{l}\text { SLNs conducted in male Albino Wistar rats } \\
\text { showed } 2.08 \text {-fold increase in relative } \\
\text { bioavailability than that of drug solution, } \\
\text { when administered orally }\end{array}$ & (97) \\
\hline & Silymarin & For liver disorders & $\begin{array}{l}\text { Greater bioavailability and lower } \\
\text { hepatotoxicity noted with the SLNs of } \\
\text { silymarin compared with commercial } \\
\text { product }\end{array}$ & (98) \\
\hline Niosomes & Rifampicin & Antibiotic & $\begin{array}{l}46.2 \% \text { of the drug was taken into the } \\
\text { lymphatic when the noisomes were } \\
\text { administered intraperitoneal route in } \\
\text { comparison with } 13.1 \% \text { for the drug } \\
\text { solution through the same route }\end{array}$ & (99) \\
\hline
\end{tabular}

Vinpocetine

For cerebrovascular disorders

NLCs

$\begin{array}{ll}\text { Testosterone } & \begin{array}{l}\text { Hormone } \\ \text { replacement }\end{array}\end{array}$

The $\mathrm{C}_{\max }$ for vinpocetine-loaded NLCs was also significantly higher than for the vinpocetine suspension. The area under the curve for the vinpocetine-loaded NLCs was 3.2-fold greater than that of the vinpocetine suspension
(100)

The lymphatically transported testosterone undecanoate accounted for between 91.5 and $99.7 \%$ of the systemically available ester

Table 3. Criteria for drugs and formulations designed for lymphotropic delivery.

\begin{tabular}{lllll}
\hline Formulation & Factor & $\begin{array}{l}\text { Criteria Favouring Lymphatic } \\
\text { Transport }\end{array}$ & Notes/Comments & Reference \\
\hline Type of lipid & $-\begin{array}{l}\text { Medium chain triglycerides } \\
\text { (e.g., Caprylic triglycerides) } \\
-\begin{array}{l}\text { Long chain triglycerides (such } \\
\text { as the ones in corn oil, olive } \\
\text { oil, pea nur oil and soybean } \\
\text { oil) }\end{array}\end{array}$ & $\begin{array}{l}\text { The long chain triglycerides support } \\
\text { the lymphatic uptake more than the }\end{array}$ & $(105)$ \\
& &
\end{tabular}




$\begin{array}{ll}\text { Carrier's Charge } & \text { Negative } \\ \text { (Zeta potential <-30 } & \\ \text { Nano-particle's size } & 10-100 \mathrm{~nm} \\ \text { Hydrophobicity } & \text { High } \\ \text { Emulsifier concentration } & <1.5 \% \mathrm{v} / \mathrm{v} \\ \text { Molecular weight } & >16,000 \mathrm{Daltons}\end{array}$

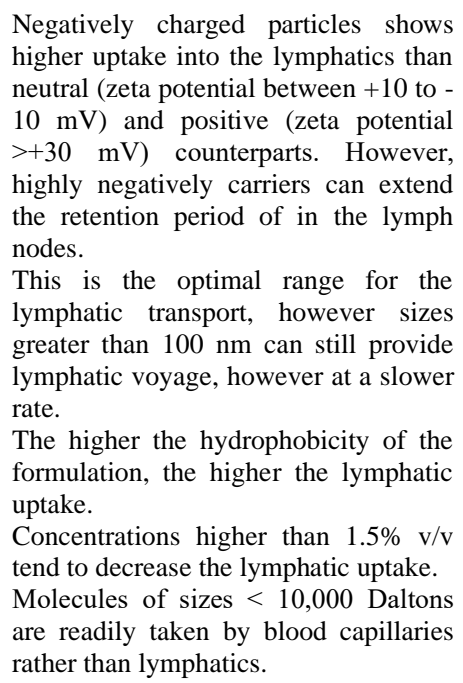
higher uptake into the lymphatics than neutral (zeta potential between +10 to $10 \mathrm{mV}$ ) and positive (zeta potential $>+30 \mathrm{mV}$ ) counterparts. However, highly negatively carriers can extend the retention period of in the lymph nodes.

This is the optimal range for the lymphatic transport, however sizes greater than $100 \mathrm{~nm}$ can still provide lymphatic voyage, however at a slower rate.

The higher the hydrophobicity of the formulation, the higher the lymphatic uptake.

Concentrations higher than $1.5 \% \mathrm{v} / \mathrm{v}$ tend to decrease the lymphatic uptake. Molecules of sizes $<10,000$ Daltons are readily taken by blood capillaries rather than lymphatics.

(106-

108)

(109)

\begin{tabular}{llll}
\hline Drug & Triglyceride solubility & $>50 \mathrm{mg} / \mathrm{mL}$ & $(111)$ \\
$\mathbf{L o g} \mathbf{P}$ & $>5$ & $(111)$
\end{tabular}

\section{REFERENCES}

1. Hansen KC, D'Alessandro A, Clement CC, Santambrogio L. Lymph formation, composition and circulation: a proteomics perspective. International Immunology. 2015;27(5):219-27.

2. Moore Jr JE, Bertram CD. Lymphatic system flows. Annual Review of Fluid Mechanics. 2018;50:459-82.

3. Breslin JW, Yang Y, Scallan JP, Sweat RS, Adderley SP, Murfee WL. Lymphatic vessel network structure and physiology. Comprehensive Physiology. 2011;9(1):20799.

4. Trevaskis NL, Kaminskas LM, Porter CJH. From sewer to saviour-targeting the lymphatic system to promote drug exposure and activity. Nature Reviews Drug Discovery. 2015;14(11):781-803.

5. Khan AA, Mudassir J, Mohtar N, Darwis Y. Advanced drug delivery to the lymphatic system: lipid-based nanoformulations. International Journal of Nanomedicine. 2013;8:2733.

6. Choi I, Lee S, Hong Y-K. The new era of the lymphatic system: no longer secondary to the blood vascular system. Cold Spring Harbor Perspectives in Medicine. 2012;2(4):a006445.

7. Suy R, Thomis S, Fourneau I. The discovery of the lymphatics in the seventeenth century. Part iii: the dethroning of the liver. Acta Chirurgica Belgica. 2016;116(6):390-7.

8. Suy R, Thomis S, Fourneau I. The discovery of lymphatic system in the seventeenth century. Part I: the early history. Acta Chirurgica Belgica. 2016;116(4):260-6.

9. Suy R, Thomis S, Fourneau I. The discovery of the lymphatic system in the seventeenth century. Part II: the discovery of Chyle vessels. Acta Chirurgica Belgica. 2016;116(5):329-35.

10. Natale G, Bocci G, Ribatti D. Scholars and scientists in the history of the lymphatic system. Journal of Anatomy. 2017;231(3):417-29.

11. Gracia G, Cao E, Feeney OM, Johnston APR, Porter $\mathrm{CJH}$, Trevaskis NL. High-density lipoprotein composition influences lymphatic transport after subcutaneous administration. Molecular Pharmaceutics. 2020;17(8):293851.

12. Ijpma FFA, van Gulik TM. "Anatomy Lesson of Frederik Ruysch" of 1670: a tribute to ruysch's contributions to lymphatic anatomy. World Journal of Surgery. 2013;37(8):19962001.

13. Di Matteo B, Tarabella V, Filardo G, Viganò A, Tomba P, Kon E, et al. Art in science: Giovanni Paolo Mascagni and the art of anatomy. Clinical Orthopaedics and Related Research ${ }^{\circledR}$. 2015;473(3):783-8.

14. Aukland K. Arnold Heller and the lymph pump. Acta Physiologica Scandinavica. 2005;185(3):171-80.

15. Louveau A, Smirnov I, Keyes TJ, Eccles JD, Rouhani SJ, Peske JD, et al. Structural and functional features of central nervous system lymphatic vessels. Nature. 2015;523(7560):337-41.

16. Ohtani O, Ohtani Y. Organization and developmental aspects of lymphatic vessels. Archives of Histology and Cytology. 2008;71(1):1-22.

17. Zoltzer H. Initial lymphatics-morphology and function of the endothelial cells. Lymphology. 2003;36(1):7-25. 
18. Baluk P, Fuxe J, Hashizume H, Romano T, Lashnits E, Butz S, et al. Functionally specialized junctions between endothelial cells of lymphatic vessels. Journal of Experimental Medicine. 2007;204(10):234962.

19. Swartz MA. The physiology of the lymphatic system. Advanced Drug Delivery Reviews. 2001;50(1-2):3-20.

20. Murfee WL, Rappleye JW, Ceballos M, Schmid-Schönbein GW. Discontinuous expression of endothelial cell adhesion molecules along initial lymphatic vessels in mesentery: the primary valve structure. Lymphatic Research and Biology. 2007;5(2):81-90.

21. Leak LV, Burke JF. Fine structure of the lymphatic capillary and the adjoining connective tissue area. American Journal of Anatomy. 1966;118(3):785-809.

22. Leak LV, Burke JF. Ultrastructural studies on the lymphatic anchoring filaments. The Journal of Cell Biology. 1968;36(1):129-49.

23. Gerli R, Solito R, Weber E, Agliano $M$. Specific adhesion molecules bind anchoring filaments and endothelial cells in human skin initial lymphatics. Lymphology. 2000;33(4):148-57.

24. Wick N, Haluza D, Gurnhofer E, Raab I, Kasimir M-T, Prinz M, et al. Lymphatic precollectors contain a novel, specialized subpopulation of podoplaninlow, CCL27expressing lymphatic endothelial cells. The American Journal of Pathology. 2008;173(4):1202-9.

25. Zöltzer H. Morphology and physiology of lymphatic endothelial cells. Encyclopedia of the Microvasculature, Biology and Pathology. 2006;83:535-44.

26. Margaris KN, Black RA. Modelling the lymphatic system: challenges and opportunities. Journal of the Royal Society Interface. 2012;9(69):601-12.

27. Ohhashi T, Fukushima S, Azuma T. Vasa vasorum within the media of bovine mesenteric lymphatics. Proceedings of the Society for Experimental Biology and Medicine. 1977;154(4):582-6.

28. Pan WR, Le Roux CM, Levy SM, Briggs CA. The morphology of the human lymphatic vessels in the head and neck. Clinical Anatomy. 2010;23(6):654-61.

29. Tortora GJ, Derrickson BH. Principles of anatomy and physiology: John Wiley \& Sons; 2018.

30. Cifarelli V, Eichmann A. The intestinal lymphatic system: functions and metabolic implications. Cellular and Molecular Gastroenterology and Hepatology. 2019;7(3):503-13.
31. Hsu MC, Itkin M. Lymphatic anatomy. Techniques in Vascular and Interventional Radiology. 2016;19(4):247-54.

32. Ilahi M, Ilahi TB. Anatomy, thorax, thoracic duct. StatPearls [Internet]: StatPearls Publishing; 2018.

33. Brotons ML, Bolca C, Fréchette É, Deslauriers J. Anatomy and physiology of the thoracic lymphatic system. Thoracic Surgery Clinics. 2012;22(2):139-53.

34. Hematti H, Mehran RJ. Anatomy of the thoracic duct. Thoracic Surgery Clinics. 2011;21(2):229-38.

35. Rehfeld A, Nylander M, Karnov K. The Immune System and the Lymphatic Organs. Compendium of Histology: Springer; 2017. p. 379-409.

36. Cesta MF. Normal structure, function, and histology of mucosa-associated lymphoid tissue. Toxicologic Pathology. 2006;34(5):599-608.

37. Verbrugghe P, Kujala P, Waelput W, Peters PJ, Cuvelier CA. Clusterin in human gutassociated lymphoid tissue, tonsils, and adenoids: localization to $\mathrm{M}$ cells and follicular dendritic cells. Histochemistry and Cell Biology. 2008;129(3):311-20.

38. Skandalakis JE, Skandalakis LJ, Skandalakis PN. Anatomy of the lymphatics. Surgical Oncology Clinics of North America. 2007;16(1):1-16.

39. Ohtani O, Ohtani Y. Structure and function of rat lymph nodes. Archives of Histology and Cytology. 2008;71(2):69-76.

40. Willard-Mack CL. Normal structure, function, and histology of lymph nodes. Toxicologic Pathology. 2006;34(5):409-24

41. Mempel TR, Henrickson SE, Von Andrian UH. T-cell priming by dendritic cells in lymph nodes occurs in three distinct phases. Nature. 2004;427(6970):154-9.

42. Muraoka D, Harada N, Hayashi T, Tahara Y, Momose F, Sawada S-i, et al. Nanogel-based immunologically stealth vaccine targets macrophages in the medulla of lymph node and induces potent antitumor immunity. ACS Nano. 2014;8(9):9209-18.

43. Bui T, Bordoni B. Anatomy, Abdomen and Pelvis, Inguinal Lymph Node. StatPearls [Internet]: StatPearls Publishing; 2020.

44. Lee JB, Zgair A, Malec J, Kim TH, Kim MG, Ali J, et al. Lipophilic activated ester prodrug approach for drug delivery to the intestinal lymphatic system. Journal of Controlled Release. 2018;286:10-9.

45. Bernier-Latmani J, Petrova TV. Intestinal lymphatic vasculature: structure, mechanisms and functions. Nature Reviews Gastroenterology and Hepatology. 2017;14(9):510. 
46. Zhang F, Zarkada G, Han J, Li J, Dubrac A, Ola $\mathrm{R}$, et al. Lacteal junction zippering protects against diet-induced obesity. Science. 2018;361(6402):599-603.

47. Hokkanen K, Tirronen A, Ylä-Herttuala S. Intestinal lymphatic vessels and their role in chylomicron absorption and lipid homeostasis. Current Opinion in Lipidology. 2019;30(5):370-6.

48. Suh SH, Choe K, Hong SP, Jeong Sh, Mäkinen T, Kim KS, et al. Gut microbiota regulates lacteal integrity by inducing VEGF-C in intestinal villus macrophages. EMBO Reports. 2019;20(4):e46927.

49. Simons M, Gordon E, Claesson-Welsh L. Mechanisms and regulation of endothelial VEGF receptor signalling. Nature reviews Molecular Cell Biology. 2016;17(10):611.

50. Kobayashi N, Takahashi D, Takano S, Kimura S, Hase K. The roles of Peyer's patches and microfold cells in the gut immune system: relevance to autoimmune diseases. Frontiers in Immunology. 2019;10:2345.

51. Ms P, Naha A, Shetty D, Nayak UY. Lymphatic Drug Transport and Associated Drug Delivery Technologies: A Comprehensive Review. Current Pharmaceutical Design. 2020.

52. Schudel A, Francis DM, Thomas SN. Material design for lymph node drug delivery. Nature Reviews Materials. 2019;4(6):415-28.

53. Chaturvedi S, Garg A, Verma A. Nano lipid based carriers for lymphatic voyage of anticancer drugs: An insight into the in-vitro, exvivo, in-situ and in-vivo study models. Journal of Drug Delivery Science and Technology. 2020:101899.

54. Stachura J, Wachowska M, Kilarski WW, Güç E, Golab J, Muchowicz A. The dual role of tumor lymphatic vessels in dissemination of metastases and immune response development. Oncoimmunology. 2016;5(7):e1182278.

55. Ma Q, Dieterich LC, Detmar M. Multiple roles of lymphatic vessels in tumor progression. Current Opinion in Immunology. 2018;53:7-12.

56. Cote B, Rao D, Alany RG, Kwon GS, Alani AWG. Lymphatic changes in cancer and drug delivery to the lymphatics in solid tumors. Advanced Drug Delivery Reviews. 2019;144:16-34.

57. Laakkonen P, Porkka K, Hoffman JA, Ruoslahti E. A tumor-homing peptide with a targeting specificity related to lymphatic vessels. Nature Medicine. 2002;8(7):751-5.

58. Timur SS, Yöyen-Ermiş D, Esendağl1 G, Yonat S, Horzum U, Esendağlı G, et al. Efficacy of a novel LyP-1-containing selfmicroemulsifying drug delivery system
(SMEDDS) for active targeting to breast cancer. European Journal of Pharmaceutics and Biopharmaceutics. 2019;136:138-46.

59. Ling R, Li Y, Yao Q, Chen T, Zhu D, Jun Y, et al. Lymphatic chemotherapy induces apoptosis in lymph node metastases in a rabbit breast carcinoma model. Journal of Drug Targeting. 2005;13(2):137-42.

60. Alrushaid S, Sayre CL, Yáñez JA, Forrest ML, Senadheera SN, Burczynski FJ, et al. Pharmacokinetic and toxicodynamic characterization of a novel doxorubicin derivative. Pharmaceutics. 2017;9(3):35.

61. Singla AK, Garg A, Aggarwal D. Paclitaxel and its formulations. International Journal of Pharmaceutics. 2002;235(1-2):179-92.

62. Videira M, Almeida AJ, Fabra À. Preclinical evaluation of a pulmonary delivered paclitaxel-loaded lipid nanocarrier antitumor effect. Nanomedicine: Nanotechnology, Biology and Medicine. 2012;8(7):1208-15.

63. Reddy LH, Sharma RK, Chuttani K, Mishra AK, Murthy RSR. Influence of administration route on tumor uptake and biodistribution of etoposide loaded solid lipid nanoparticles in Dalton's lymphoma tumor bearing mice. Journal of Controlled Release. 2005;105(3):185-98.

64. Paliwal R, Rai S, Vaidya B, Khatri K, Goyal AK, Mishra N, et al. Effect of lipid core material on characteristics of solid lipid nanoparticles designed for oral lymphatic delivery. Nanomedicine: Nanotechnology, Biology and Medicine. 2009;5(2):184-91.

65. Zara GP, Bargoni A, Cavalli R, Fundarò A, Vighetto D, Gasco MR. Pharmacokinetics and tissue distribution of idarubicin-loaded solid lipid nanoparticles after duodenal administration to rats. Journal of Pharmaceutical Sciences. 2002;91(5):132433.

66. Lawson KA, Anderson K, Snyder RM, Simmons-Menchaca M, Atkinson J, Sun L-Z, et al. Novel vitamin E analogue and 9-nitrocamptothecin administered as liposome aerosols decrease syngeneic mouse mammary tumor burden and inhibit metastasis. Cancer Chemotherapy and Pharmacology. 2004;54(5):421-31.

67. Xie Y, Aillon KL, Cai S, Christian JM, Davies NM, Berkland CJ, et al. Pulmonary delivery of cisplatin-hyaluronan conjugates via endotracheal instillation for the treatment of lung cancer. International Journal of Pharmaceutics. 2010;392(1-2):156-63.

68. Cai S, Xie Y, Davies NM, Cohen MS, Forrest ML. Carrier-based intralymphatic cisplatin chemotherapy for the treatment of metastatic squamous cell carcinoma of the head \& neck. Therapeutic Delivery. 2010;1(2):237-45. 
69. Schwager S, Detmar M. Inflammation and lymphatic function. Frontiers in Immunology. 2019;10:308.

70. Smedby KE, Ponzoni M. The aetiology of B-cell lymphoid malignancies with a focus on chronic inflammation and infections. Journal of Internal Medicine. 2017;282(5):360-70.

71. Mezu-Ndubuisi OJ, Maheshwari A. The role of integrins in inflammation and angiogenesis. Pediatric Research. 2020:1-8.

72. Lane RS, Femel J, Breazeale AP, Loo CP, Thibault G, Kaempf A, et al. IFN $\gamma$-activated dermal lymphatic vessels inhibit cytotoxic $\mathrm{T}$ cells in melanoma and inflamed skin. Journal of Experimental Medicine. 2018;215(12):3057-74.

73. Teijeira A, Hunter MC, Russo E, Proulx ST, Frei T, Debes GF, et al. T cell migration from inflamed skin to draining lymph nodes requires intralymphatic crawling supported by ICAM-1/LFA-1 interactions. Cell Reports. 2017;18(4):857-65.

74. Ge Y, Li Y, Gong J, Zhu W. Mesenteric organ lymphatics and inflammatory bowel disease. Annals of Anatomy-Anatomischer Anzeiger. 2018;218:199-204.

75. Bouta EM, Bell RD, Rahimi H, Xing L, Wood RW, Bingham CO, et al. Targeting lymphatic function as a novel therapeutic intervention for rheumatoid arthritis. Nature Reviews Rheumatology. 2018;14(2):94-106.

76. Aldrich MB, Velasquez FC, Kwon S, Azhdarinia A, Pinkston K, Harvey BR, et al. Lymphatic delivery of etanercept via nanotopography improves response to collagen-induced arthritis. Arthritis Research and Therapy. 2017;19(1):1-13.

77. Shinriki S, Jono H, Ueda M, Ota K, Ota T, Sueyoshi $\mathrm{T}$, et al. Interleukin-6 signalling regulates vascular endothelial growth factor-C synthesis and lymphangiogenesis in human oral squamous cell carcinoma. The Journal of Pathology. 2011;225(1):142-50.

78. Polzer K, Baeten D, Soleiman A, Distler J, Gerlag DM, Tak PP, et al. Tumour necrosis factor blockade increases lymphangiogenesis in murine and human arthritic joints. Annals of the Rheumatic Diseases. 2008;67(11):1610-6.

79. Escobedo N, Oliver G. The lymphatic vasculature: its role in adipose metabolism and obesity. Cell Metabolism. 2017;26(4):598-609.

80. Rehal S, Kataru RP, Hespe GE, Baik JE, Park HJ, Ly C, et al. Regulation of lymphatic function and injury by nitrosative stress in obese mice. Molecular Metabolism. 2020;42:101081.

81. Chachaj A, Puła B, Chabowski M, Grzegrzółka J, Szahidewicz-Krupska E,
Karczewski M, et al. Role of the Lymphatic System in the Pathogenesis of Hypertension in Humans. Lymphatic Research and Biology. 2018;16(2):140-6.

82. Csányi G, Singla B. Arterial lymphatics in atherosclerosis: old questions, new insights, and remaining challenges. Journal of Clinical Medicine. 2019;8(4):495.

83. Zheng Z, Ren K, Peng X, Zhu X, Yi G. Lymphatic vessels: a potential approach to the treatment of atherosclerosis? Lymphatic Research and Biology. 2018;16(6):498-506.

84. Nayak Y, Avadhani K, Mutalik S, Y Nayak U. Lymphatic delivery of anti-HIV drug nanoparticles. Recent Patents on Nanotechnology. 2016;10(2):116-27.

85. Qin C, Chu Y, Feng W, Fromont C, He S, Ali J, et al. Targeted delivery of lopinavir to HIV reservoirs in the mesenteric lymphatic system by lipophilic ester prodrug approach. Journal of Controlled Release. 2020.

86. Williams JB, Hüppner A, Mulrooney-Cousins PM, Michalak TI. Differential expression of woodchuck toll-like receptors $1-10$ in distinct forms of infection and stages of hepatitis in experimental hepatitis B virus infection. Frontiers in Microbiology. 2018;9:3007.

87. Uzzan M, Corcos O, Martin JC, Treton X, Bouhnik Y. Why is SARS-CoV-2 infection more severe in obese men? The gut lymphatics - Lung axis hypothesis. Medical Hypotheses. 2020;144:110023.

88. Sathekge M, Maes A, Kgomo M, Van de Wiele C. Fluorodeoxyglucose uptake by lymph nodes of HIV patients is inversely related to CD4 cell count. Nuclear Medicine Communications. 2010;31(2):137-40.

89. Kinman L, Brodie SJ, Tsai CC, Bui T, Larsen $\mathrm{K}$, Schmidt A, et al. Lipid-drug association enhanced HIV-1 protease inhibitor indinavir localization in lymphoid tissues and viral load reduction: A proof of concept study in HIV2287-infected macaques. Journal of Acquired Immune Deficiency Syndromes. 2003;34(4):387-97.

90. Holm R, Porter CJH, Edwards GA, Müllertz A, Kristensen HG, Charman WN. Examination of oral absorption and lymphatic transport of halofantrine in a triple-cannulated canine model after administration in selfmicroemulsifying drug delivery systems (SMEDDS) containing structured triglycerides. European Journal of Pharmaceutical Sciences. 2003;20(1):91-7.

91. Beg S, Swain S, Singh HP, Patra CN, Rao MEB. Development, optimization, and characterization of solid self-nanoemulsifying drug delivery systems of valsartan using porous carriers. AAPS Pharmscitech. 2012;13(4):1416-27. 
92. Thakkar H, Nangesh J, Parmar M, Patel D. Formulation and characterization of lipidbased drug delivery system of raloxifenemicroemulsion and self-microemulsifying drug delivery system. Journal of Pharmacy and Bioallied Sciences. 2011;3(3):442.

93. Sheue Nee Ling S, Magosso E, Abdul Karim Khan N, Hay Yuen K, Anne Barker S. Enhanced oral bioavailability and intestinal lymphatic transport of a hydrophilic drug using liposomes. Drug Development and Industrial Pharmacy. 2006;32(3):335-45.

94. Cavalli R, Zara GP, Caputo O, Bargoni A, Fundarò A, Gasco MR. Transmucosal transport of tobramycin incorporated in SLN after duodenal administration to rats. Part IA pharmacokinetic study. Pharmacological Research. 2000;42(6):541-5.

95. Venkateswarlu V, Manjunath K. Preparation, characterization and in vitro release kinetics of clozapine solid lipid nanoparticles. Journal of Controlled Release. 2004;95(3):627-38.

96. Sanjula B, Shah FM, Javed A, Alka A. Effect of poloxamer 188 on lymphatic uptake of carvedilol-loaded solid lipid nanoparticles for bioavailability enhancement. Journal of Drug Targeting. 2009;17(3):249-56.

97. Chalikwar SS, Belgamwar VS, Talele VR, Surana SJ, Patil MU. Formulation and evaluation of Nimodipine-loaded solid lipid nanoparticles delivered via lymphatic transport system. Colloids and Surfaces B: Biointerfaces. 2012;97:109-16.

98. Yang KY, Du Hyeong Hwang AMY, Kim DW, Shin Y-J, Bae O-N, Kim Y, II, et al. Silymarin-loaded solid nanoparticles provide excellent hepatic protection: physicochemical characterization and in vivo evaluation. International Journal of Nanomedicine. 2013;8:3333.

99. Jain CP, Vyas SP, Dixit VK. Niosomal system for delivery of rifampicin to lymphatics. Indian Journal of Pharmaceutical Sciences. 2006;68(5).

100. Zhuang C-Y, Li N, Wang M, Zhang X-N, Pan W-S, Peng J-J, et al. Preparation and characterization of vinpocetine loaded nanostructured lipid carriers (NLC) for improved oral bioavailability. International Journal of Pharmaceutics. 2010;394(1-2):17985.

101. Shackleford DM, Faassen WAF, Houwing N, Lass H, Edwards GA, Porter CJH, et al. Contribution of lymphatically transported testosterone undecanoate to the systemic exposure of testosterone after oral administration of two andriol formulations in conscious lymph duct-cannulated dogs. Journal of Pharmacology and Experimental Therapeutics. 2003;306(3):925-33.
102. Jain RK. Barriers to drug delivery in solid tumors. Scientific American. 1994;271(1):5865.

103. Harvey AJ, Kaestner SA, Sutter DE, Harvey NG, Mikszta JA, Pettis RJ. Microneedlebased intradermal delivery enables rapid lymphatic uptake and distribution of protein drugs. Pharmaceutical Research. 2011;28(1):107-16.

104. Zhang Z, Lu Y, Qi J, Wu W. An update on oral drug delivery via intestinal lymphatic transport. Acta Pharmaceutica Sinica B. 2021.

105. Yáñez JA, Wang SWJ, Knemeyer IW, Wirth MA, Alton KB. Intestinal lymphatic transport for drug delivery. Advanced Drug Delivery Reviews. 2011;63(10-11):923-42.

106. Holm R, Hoest J. Successful in silico predicting of intestinal lymphatic transfer. International Journal of Pharmaceutics. 2004;272(1-2):189-93.

107. Porter CJH. Drug delivery to the lymphatic system. Critical Reviews in Therapeutic Drug Carrier Systems. 1997;14(4):333-94.

108. Clogston JD, Patri AK. Zeta potential measurement. Characterization of nanoparticles intended for drug delivery: Springer; 2011. p. 63-70.

109. Oussoren C, Zuidema J, Crommelin DJA, Storm G. Lymphatic uptake and biodistribution of liposomes after subcutaneous injection.: II. Influence of liposomal size, lipid composition and lipid dose. Biochimica et Biophysica Acta (BBA)Biomembranes. 1997;1328(2):261-72.

110. Hawley AE, Davis SS, Illum L. Targeting of colloids to lymph nodes: influence of lymphatic physiology and colloidal characteristics. Advanced Drug Delivery Reviews. 1995;17(1):129-48.

111. Charman WNA, Stella VJ. Estimating the maximal potential for intestinal lymphatic transport of lipophilic drug molecules. International Journal of Pharmaceutics. 1986;34(1-2):175-8. 